\title{
Perfect Price Discrimination with Costless Arbitrage
}

\author{
Joshua S. Gans and Stephen P. King \\ Intellectual Property Research Institute of Australia \\ The University of Melbourne \\ Intellectual Property Research Institute of Australia \\ Working Paper No. 17/05 \\ ISSN 1447-1795 \\ August 2005 \\ Intellectual Property Research Institute of Australia \\ The University of Melbourne \\ Law School Building \\ Victoria 3010 Australia \\ Telephone: 61 (0) 383441127 \\ Fax: 61 (0) 393482353 \\ Email: info@ipria.org \\ www.ipria.org
}




\title{
Perfect Price Discrimination with Costless Arbitrage*
}

\author{
by \\ Joshua S. Gans and Stephen P. King ${ }^{* *}$ \\ First Draft: $22^{\text {nd }}$ September, 2004 \\ This Version: 20 $0^{\text {th }}$ June, 2005
}

\begin{abstract}
The ability of a monopoly seller to prevent resale is often presented as a necessary condition for first degree and third degree price discrimination. In this paper, we explore this claim and show that, even with costless arbitrage markets, price discrimination may continue to be both feasible and profit maximising despite potential resale. With finite numbers of consumers, arbitrage markets may be 'thin', in the sense that there can be too few low-valuation consumers to supply high-valuation consumers. We examine both ex ante and ex post arbitrage markets and show how a monopoly can exploit potential 'thinness' to profitably price discriminate. In each case, we present sufficient conditions for equilibrium price discrimination. We note that the form of such discrimination depends on the nature of the arbitrage market and consider business strategies that a monopoly might adopt to exacerbate market thinness. Our results show how market depth and the effectiveness of arbitrage are the key elements for price discrimination, rather than the per se prevention of reselling. These pricing strategies are critically important in the efficient management of intellectual property. Journal of Economic Literature Classification Numbers: D42, L11
\end{abstract}

Keywords: price discrimination, arbitrage, personalised pricing, group pricing, intellectual property

\footnotetext{
* We thank Michael Ryall for helpful discussions and the Intellectual Property Research Institute for Australia for financial support. Of course, responsibility for all errors lies with the authors.

** Melbourne Business School, University of Melbourne and Australian Competition and Consumer Commission, respectively. All views in this document are those of the author and should not be construed as representing those of the above organisations.
} 


\section{Introduction}

According to most treatments (e.g., Varian, 1989), price discrimination requires firms to (1) have some market power, (2) be able to sort consumers and (3) be able to prevent resale. When it comes to the benchmark case of first degree or perfect price discrimination the first two conditions become stronger in that the firm must also be able to make take it or leave it offers to consumers and possess perfect information regarding a consumer's type.

It is commonly asserted that this change to the standard treatment undermines the possibility of price discrimination. Consider, for instance:

It is clear that if the transaction (arbitrage) costs between two consumers are low, any attempt to sell a given good to two consumers at different prices runs into the problem that the low-price consumer buys the good to resell it to the high-price one. (Tirole, 1988, p.134)

To our knowledge there have been no attempts to model the resale market to test whether it is in fact true that this possibility undermines price discrimination. ${ }^{1}$

This paper explores the possibility of first degree price discrimination in an environment where (3), the no resale condition, is not satisfied. Indeed, we assume the opposite: that resale can occur free of transaction or transportation costs. Moreover, we assume that any trader - the monopolist producer or arbitrageurs - can make take it or leave it offers to any consumer and knows that consumer's type. Despite the complete relaxation of the no resale condition, we demonstrate that price discrimination is still both feasible and potentially profitable for a monopolist seller.

Consequently, the main contribution of this paper is to demonstrate, contrary to conventional wisdom, that price discrimination is still possible even under costless arbitrage. In a model with two consumer types and a monopolist with unlimited capacity, we model two variants of resale. In the first, following an initial round of sales by the monopolist, the monopolist and initial purchasers can act as sellers in an ex post market. We term this ex post arbitrage. In this situation, we demonstrate that there are conditions

\footnotetext{
${ }^{1}$ An exception is Alger (1999) who demonstrates that arbitrage, in a model where consumer types are private information, can eliminate price discrimination.
} 
under which the monopolist sells to all consumers initially and charges high-valuation types a higher price than the price to low-valuation types. The possibility of ex post arbitrage constrains the monopolist's pricing to high-valuation consumers but does not prevent them from engaging in price discrimination. The reason is that, in equilibrium, the high-valuation consumers are not certain that low-valuation consumers will trade in the ex post market and are, therefore, willing to accept a higher up-front price. There is no discounting or risk aversion driving this result although the presence of either would strengthen it.

In the second variant, we consider forward markets for the sale of the monopolist's product. In these markets, low-valuation consumers can sell forward contracts to high-valuation ones and settle these by purchasing the requisite stock from the monopolist later on. In this situation, it may be worthwhile for the monopolist to set a pricing policy equivalent to a perfect price discrimination outcome whereby each consumer is charged their willingness to pay. This is because the monopolist has an incentive to speculate on there being insufficient low types for trade to have occurred in the forward market rather than foreclosing on that possibility by setting a single high price.

In each case, it is the possibility that a re-sale market may be 'thin' that drives the result. Put simply, when a monopolist can observe a consumer's type, the low-valuation consumers are those who can perform an arbitrage as well as a consumption function. The monopolist can choose to foreclose on these by not selling to those consumers (i.e., charging a high price) or, if there is a strong enough possibility that the numbers of such consumers may be low, sell to them and price discriminate. As such, the chief contribution of this paper is to identify a new condition that permits price discrimination to arise - the expected number of low type consumers - and, in so doing, improve our understanding of the foundations of price discrimination. In addition, while our model is extreme in that a monopolist can perfectly observe a consumer's type and competition in the re-sale market is strong, it identifies strategies that enhance expectations that re-sale markets will be thin, such as volume purchase constraints, which may accompany practices of price discrimination. 
This contribution is timely in that advances in electronic commerce appear to have brought about an enhanced ability for seller's to identify the willingnesses-to-pay of their customers as well as an increased ability for consumers to engage in competition with sellers in after-markets (e.g., through eBay). For instance, Choudhary et.al. (2005) document a number of new attempts at personalised pricing (the modern term for first degree price discrimination; Shapiro and Varian, 1999) including Amazon.com's Gold Box which gives users a selection of discounts on products they might wish to purchase at the margin. There is also a seemingly regular practice of personalised pricing in the market for servers where suppliers routinely calculate a customer's return on investment and price on that basis. By looking at a substantial weakening of one of the key standard assumptions in first degree price discrimination but still finding that it is feasible our paper suggests why personalised pricing may not be the textbook curiosity it is sometimes taken as. In particular, we demonstrate that when the overall number of consumers in a market is low, price discrimination is more likely to be sustainable.

However, it should be noted that the model below is also a foundation for third degree price discrimination (or 'group pricing' in modern jargon; Shapiro and Varian, 1999). The high and low types could merely be identifiers for the group a consumer belongs to. In this respect, our model finds conditions under which a firm could charge different prices to different groups even in the presence of a strong re-sale market. Again, the key condition relies on the expected thinness of that re-sale market. For instance, when theatre owners give students discounts, our model suggests that this will only be sustainable if others are uncertain as to the number of students purchasing tickets or if there are limitations on the total volume of tickets sold to students.

The paper proceeds as follows. Section 2 outlines the basic model structure and the textbook case of perfect price discrimination; to serve as a benchmark. Section 3 considers the case of ex post arbitrage while Section 4 analyses what happens if there is an ex ante or forward market. A final section concludes. 


\section{The Model and Perfect Price Discrimination}

We consider a simple setting where there is a finite set of $n$ consumers in a market who each value one unit (and only one unit) of a product manufactured by a single producer, $M$. The producer's marginal cost of production is a constant $c$ per unit. $M$ is not capacity constrained in any time period.

There are two 'types' of consumers who differ according to their willingness-topay for M's product: $L$ types $(L)$ who value the product at $\underline{v}$ and $H$ types $(H)$ who value it at $\bar{v}$, where $\underline{v}<\bar{v}$. We assume that $\underline{v}>c$. The probability that any given consumer has a low valuation is $\pi$ and this probability is independent across consumers. To avoid trivial outcomes, we assume that $\pi$ is strictly between zero and one. Finally, the model below involves two periods but we assume that there is no discounting on the part of consumers or $M^{2}$

A standard approach to perfect price discrimination shows how the profitmaximising prices set by $M$ differ according to the information available to $M$. To see this, suppose that $M$ has no information about any consumer's type, consumers have no interaction with each other either before or after dealing with $M$ and that $M$ must set prices prior to any consumer purchasing its product. In this situation, $M$ will post a single price, $p$, for all consumers. There are two alternative profit-maximizing prices that $M$ could set. First, $M$ could set $p=\underline{v}$. Its expected profit per consumer will be $\underline{v}-c$ and it makes sales to all $n$ consumers. Alternatively, $M$ could set $p=\bar{v}$. Only $H$-types purchase the product and $M$ 's expected profit per consumer is $(1-\pi)(\bar{v}-c) .^{3} M$ will choose the price that maximises the expected profit per customer.

In contrast, suppose that consumers have no direct interaction with each other and that $M$ must set prices prior to any consumer purchasing its product, but allow $M$ to observe a consumer's type prior to sale. That is, the minute a consumer walks into a store their type is revealed to $M$ and $M$ can make that customer a take it or leave it offer. Then it is profit maximising for $M$ to set two prices; a price to $L$ types of $\underline{p}=\underline{v}$ and to $H$ types

\footnotetext{
${ }^{2}$ This avoids trivial cases where price discrimination might arise because some consumers prefer to buy off a monopolist at a high price today rather than wait for a lower price in the future. In other words, this assumption removes one potential source of price discrimination.

${ }^{3}$ It is straightforward to show that other possible prices are not profit maximising for $M$.
} 
of $\bar{p}=\bar{v}$ giving it expected profits per consumer of $(1-\pi) \bar{v}+\pi \underline{v}-c$. This is the textbook outcome from perfect price discrimination.

In the analysis below we retain the assumptions required for perfect price discrimination - monopoly power and consumer type observability - except that we will allow consumers to interact with each other either after purchasing from $M$ or before purchasing from $M$. In other words, $M$ is able to set two type-contingent prices for consumers prior to making any sales and will be able to observe the type of any individual consumer prior to making a sale. ${ }^{4}$ Thus, $M$ will be able to make each consumer a take it or leave it offer at the price set for that consumer's type. We denote the take it or leave it price offers as $\bar{p}$ and $\underline{p}$ to $H$ and $L$ types respectively. As with the example of perfect price discrimination given above, before setting its prices $M$ does not know for sure how many consumers of a given type there are in the market. Similarly, while consumers know their own valuation they do not know the valuations of other consumers and, thus, do not know for sure the number of $H$ and $L$ consumers in the population.

Unlike the example of perfect price discrimination, however, consumers will be able to meet and to trade with each other either prior to purchasing from $M$ or after purchasing from $M$. If consumers meet after purchasing from $M$ then they may trade the relevant product. We refer to this as ex post arbitrage. If consumers meet before purchasing from $M$ then they will be able to trade 'futures contracts' for delivery of the relevant product. We refer to this as ex ante arbitrage.

\section{Ex Post Arbitrage}

First, consider the situation where consumers are able to interact and trade after the initial round of sales from $M$. The timing for this is as follows:

PERIOD 1: $M$ makes (unit) price offers of $\bar{p}$ and $\underline{p}$ to $H$ and $L$ types respectively and consumers choose their quantities. ${ }^{5}$

\footnotetext{
${ }^{4}$ We can think of $M$ as making all sales simultaneously to all consumers. This avoids issues of information gathering and potential signaling by $M$ that may arise, for example, through a sequential sales process. These issues, while interesting in their own right, are orthogonal to our interests here.

${ }^{5}$ Our general result for ex post arbitrage does not depend on whether or not $L$ consumers are prevented from purchasing multiple units in period 1 . We explain this below.
} 
PERIOD 2: $M$ and purchasers in period 1 compete on the basis of price to sell to any consumers who chose not to purchase in period 1 . All consumers holding the product at the end of the period consume it.

Thus, $M$ makes an initial round of sales to prospective consumers. Some of those may purchase while others may choose to wait until the ex post market. In that market, $M$ and purchasers in the initial round both have the opportunity to sell to any remaining consumers.

Our aim here is to consider whether price discrimination remains viable in period 1 despite the existence of a well-functioning ex post arbitrage market. Price discrimination will arise in period 1 if it is profit maximising for $M$ to set prices $\bar{p}>\underline{p} \geq \underline{v}$ with at least some of each type of consumer buying at their relevant price in the first period. Clearly, behaviour in the first period will depend on expectations about the arbitrage market. As such, the form of competition and price formation in the period 2 market is critical.

In that respect, we make two key assumptions. First, as noted above, if there is competition in the period 2 market (i.e., there is more than one seller), competition is on the basis of price. This assumption means that competition in the period 2 market will be as intense as possible. Second, if $M$ continues to be a monopolist in the period 2 market, then $M$ is able to perfectly price discriminate. This assumption is natural given that we have assumed that the monopolist has that ability period 1 . Given these assumptions, we denote the period 2 price by $p_{r}$, noting that this price depends on the exact nature of period 1 trades.

Our aim is to analyse situations where consumers who face a low period 1 price are able to profitably trade to $H$ consumers in period 2 . This can arise either where an $L$ consumer buys a single unit in the first period but then resells that unit in period two because $p_{r}>\underline{v}$, or where an $L$ consumer buys multiple units in the first period intending to resell excess units in period 2. Thus, we do not wish to rule out the possibility that $L$ consumers could purchase more than a single unit in the first period. However, we assume that those consumers will only purchase 'extra' units if they expect that such a purchase will be strictly profitable. 
There are some clear implications of these assumptions on the operation of the period 2 market:

- If there are no $L$ consumers then the period 2 price will be $\bar{v}$. This arises because no $H$ consumer that purchases in period 1 will sell for less than $\bar{v}$ in period 2, unless they have bought multiple units. But purchasing multiple units can never be expected to be strictly profitable for one $H$ type as it would involve selling to another $H$ type in period 2 who would then expect to be better off purchasing in period 1 .

- If there are no $H$ consumers in period 2 or if there is at least one $L$ consumer and all $H$ consumers purchase in period 1 then the period 2 price is no greater than $\underline{v}$. This is a direct implication of the fact that no $L$ consumer will pay more than $\underline{v}$ in period 2.

- The realised period 2 price can only be strictly less than $\underline{v}$ if at least one $L$ consumer makes multiple purchases in period 1. If an $L$ consumer has multiple units, their opportunity cost of selling the marginal unit is 0 . Otherwise, for those consumers their opportunity cost is $\underline{v}$ so $M$ can set a period 2 price of $\underline{v}$ and still make sales.

Finally, note that the period 2 price is non-decreasing in the number of $H$ consumers. In other words, given period 1 prices and type-contingent purchases, if there is one more $H$ consumer in period 2 (and as such one less $L$ consumer) this may increase the realised period 2 price, but it cannot decrease this price.

Immediately after $M$ sets specific period 1 prices but prior to any purchases, both $M$ and consumers will have expectations of the second period price. These expectations, however, will depend on each agent's identity. When $M$ sets the period 1 prices it has no information about the specific types of any consumers. Its expected period 2 price, conditional on the prices that it sets in period 1 , is denoted by $E\left[p_{r}\right]$. In contrast, as consumers know their own type, they have some information that is relevant to the second period price. Thus, we denote the expected period 2 equilibrium price, from the perspective of an $L$ consumer in period 1 , by $E\left[p_{r} ; L\right]$ and the expected period 2 equilibrium price from the perspective of an $H$ consumer in period 1, by $E\left[p_{r} ; H\right]$. 
To see how these expected prices differ, let $\Pi(k)$ denote the ex ante probability that there are exactly $k L$-type consumers. Thus $\Pi(k)=C_{k}^{n}(1-\pi)^{n-k} \pi^{k}$. Further, given the prices set by $M$ in period 1 , let $p_{r}(k)$ be the realised equilibrium period two price given that there are actually $k L$-type consumers. Then:

$$
\begin{gathered}
E\left[p_{r}\right]=\Pi(0) p_{r}(0)+\Pi(1) p_{r}(1)+\ldots+\Pi(n) p_{r}(n) \\
E\left[p_{r} ; L\right]=\frac{1}{1-\Pi(0)}\left(\Pi(1) p_{r}(1)+\ldots+\Pi(n) p_{r}(n)\right) \\
E\left[p_{r} ; H\right]=\frac{1}{1-\Pi(n)}\left(\Pi(0) p_{r}(0)+\ldots+\Pi(n-1) p_{r}(n-1)\right)
\end{gathered}
$$

In order to examine whether profitable price discrimination is possible, we need to consider the potential outcomes from trade if $M$ tries to price discriminate. Consider the subgame after $M$ has set period 1 prices $\bar{p}>\underline{p} \geq \underline{v}$ but prior to any consumer purchasing. Given our assumptions about the period 2 market we can make a number of observations about consumers' expectations regardless of the exact prices set by $M$. First, note that $E\left[p_{r} ; H\right] \geq E\left[p_{r} ; L\right]$. This follows as period 2 prices are non-decreasing in the number of $H$ consumers. Second, $E\left[p_{r} ; L\right] \geq \underline{v}$. To see this, suppose the converse, that $E\left[p_{r} ; L\right]<\underline{v}$. Remember that the realised period 2 price can only fall below $\underline{v}$ if at least one $L$ consumer makes multiple purchases in the first period, so $E\left[p_{r} ; L\right]<\underline{v}$ can only arise if in equilibrium at least one $L$ consumer is expected to make multiple purchases. But this cannot occur. Given $\underline{p} \geq \underline{v}$, if $E\left[p_{r} ; L\right]<\underline{v}$, then multiple purchases would lead to an expected loss for the relevant $L$ consumer. Thus, we have a contradiction and it cannot be the case that $E\left[p_{r} ; L\right]<\underline{v}$. Third, note that, as the following lemma demonstrates, $E\left[p_{r} ; H\right]$ is strictly bounded away from $\underline{v}$.

Lemma 1: Given any period 1 prices set by $M, E\left[p_{r} ; H\right] \geq \frac{1-\Pi(0)-\Pi(n)}{1-\Pi(n)} \underline{v}+\frac{\Pi(0)}{1-\Pi(n)} \bar{v}$.

PROOF: Remember that $E\left[p_{r} ; L\right] \geq \underline{v}$ and $p_{r}(n) \leq \underline{v}$. It immediately follows that the expected price given there is at least one $L$ consumer and at least one $H$ consumer is at least $\underline{v}$. In other words:

$$
\Gamma=\frac{E\left[p_{r} ; L\right]-\frac{\Pi(n)}{1-\Pi(0)} p_{r}(n)}{1-\frac{\Pi(n)}{1-\Pi(0)}}=\frac{1}{1-\Pi(0)-\Pi(n)}\left(\Pi(1) p_{r}(1)+\ldots+\Pi(n-1) p_{r}(n-1)\right) \geq \underline{v}
$$


But, $E\left[p_{r} ; H\right]=\frac{1-\Pi(0)-\Pi(n)}{1-\Pi(n)} \Gamma+\frac{\Pi(0)}{1-\Pi(n)} p_{r}(0)$. Noting that $\Gamma \geq \underline{v}$ and $p_{r}(0)=\bar{v}$ this implies that $E\left[p_{r} ; H\right] \geq \frac{1-\Pi(0)-\Pi(n)}{1-\Pi(n)} \underline{v}+\frac{\Pi(0)}{1-\Pi(n)} \bar{v}$.

Because $\Pi(0)>0$, Lemma 1 implies that $E\left[p_{r} ; H\right]$ is always strictly greater than $\underline{v}$ regardless of the prices set by $M$ in period 1 . In particular, if we let $v^{*}=\frac{1-\Pi(0)-\Pi(n)}{1-\Pi(n)} \underline{v}+\frac{\Pi(0)}{1-\Pi(n)} \bar{v}$ then $E\left[p_{r} ; H\right] \geq v^{*}>\underline{v}$ regardless of the period 1 prices.

To show that (non-trivial) price discrimination is possible despite the existence of an ex post arbitrage market, suppose that $M$ sets $\underline{p}=\underline{v}$ and $\bar{p}=v^{*}$ in period 1 . Then it immediately follows from Lemma 1 that all $H$ consumers will purchase one unit of the product in period 1. Waiting only leads to a higher expected price for these consumers. Given that all $H$ consumers buy in period 1, the expected price for $L$ consumers must be no greater than $\underline{v}$. Indeed, as $E\left[p_{r} ; L\right] \geq \underline{v}$ this means that $E\left[p_{r} ; L\right]=\underline{v}$ and all $L$ consumers will purchase one and only one unit in period 1 . In period 2, there is no trade with the realised arbitrage price equal to $\underline{v}$ if there is at least one $L$ consumer and $\bar{v}$ otherwise. Thus, if $M$ sets $\underline{p}=\underline{v}$ and $\bar{p}=v^{*}$ in period 1 the unique equilibrium of the following subgame is that all consumers purchase in the first period and there is no trade in period 2.

It remains to show however that such price discrimination is profitable for $M$. Because $v^{*}>\underline{v}$ it follows that $M$ will always prefer to price discriminate rather than set a uniform low price to consumers. However, $M$ could set a uniform price $p=\bar{v}$ in period 1. This yields expected profits of $(1-\pi)(\bar{v}-c)$ per consumer. In contrast, setting $p=\underline{v}$ and $\bar{p}=v^{*}$ in period 1 will yield expected per consumer profits of $(1-\pi) v^{*}+\pi \underline{v}-c$. Comparing these profit levels and substituting in for $v^{*}$ leads immediately to Proposition 1.

Proposition 1: The producer $M$ will always price discriminate in period 1 if

$$
\pi(\underline{v}-c)-(1-\pi) \frac{1-\Pi(n)-\Pi(0)}{1-\Pi(n)}(\bar{v}-\underline{v})>0 .
$$

Thus, if either the probability of any individual consumer being $L$ is high enough and/or if $\bar{v}$ is close enough to $\underline{v}$ then $M$ will always price discriminate in period 1 . This makes 
intuitive sense. In the face of ex post arbitrage, price discrimination allows $M$ to gain profits from $L$ consumers as well as $H$ consumers. However, the existence of the arbitrage market limits the amount of surplus that $M$ can extract from the high valuation consumers. Thus, price discrimination is only optimal for $M$ if the gain in profit from low valuation consumers offsets the loss in profit from $H$ consumers.

The reason why the period 2 arbitrage market does not eliminate price discrimination is evident from the definition of $v^{*}$. Note that as $\Pi(0)$ approaches zero (for example as $n$ becomes large), $v^{*}$ approaches $\underline{v}$ and the scope for profitable price discrimination falls. Thus, the ability of $M$ to price discriminate critically depends on the likelihood of the event that there will be no $L$ consumers in the second period so that any $H$ consumer who fails to buy in the first period will face the risk of a high price in the second period. It is the risk that there are no $L$ consumers that undermines the effectiveness of ex post arbitrage.

It could be argued that our modified price discrimination only arises because we have artificially constrained $M$ in period 1 . After all, within our model, it is optimal for $M$ to refuse to make any sales in period 1 and then simply to perfectly price discriminate in the second period. While true, this potential criticism misses the importance of ex post arbitrage. The initial seller cannot stop consumers interacting after an initial round of sales and it is this interaction that limits the ability to price discriminate. Our key insight is that while price discrimination is limited it is not eliminated by ex post arbitrage.

Alternatively, it could be argued that we allow too much freedom for $M$. In particular, we have assumed that $M$ can trade in the ex post market. What if this cannot occur? There seems little reason why $M$ should be excluded from the ex post market and indeed, to the extent that $M$ is unable to commit not to participate in this market, we would expect such participation to reduce M's market power. However, none of our conclusions rely on M's participation in the period 2 market. Rather, our assumptions about the period 2 market remain reasonable even if $M$ is unable to participate in that market. If there are no $L$ consumers then the period 2 price will be $\bar{v}$ regardless of M's participation. If there are no $H$ consumers in period 2 or if there is at least one $L$ consumer and all $H$ consumers purchase in period 1 then the period 2 price should still is no greater than $\underline{v}$ even if $M$ is absent from the period 2 market. And even without $M$ 
selling in period 2, the realised period 2 price can only be strictly less than $\underline{v}$ if at least one $L$ consumer makes multiple purchases in period 1 . Indeed, the only assumption that would need to be altered relates to the situation where no consumers purchase. In this case there is demand but no supply and the period 2 price is simply a number greater than $\bar{v}$. Again this does not alter our analysis. As such, Proposition 1 remains valid even if $M$ is unable to participate in the ex post arbitrage market.

Finally, it should be noted that we have not solved for the actual price discrimination equilibrium in deriving Proposition 1. Rather, we have presented sufficient conditions so that $M$ will always choose to price discriminate in period 1 . To solve for the actual price discrimination equilibrium, we need significantly more structure on the period 2 market. However, we have shown that, given our relatively modest assumptions about the ex post arbitrage market, the actual market equilibrium will always involve price discrimination so long as the condition presented in Proposition 1 holds.

In summary, what we have demonstrated here is that the traditional intuition that sufficient ex post competition amongst consumers - effectively speculators - and the monopolist can eliminate price discrimination does not necessarily hold. This is because the monopolist is able to exploit the risk that the ex post market is thin and charge $H$ types a higher price. The concern about thinness comes because to be an arbitrageur a consumer must be an $L$ type; as the monopolist cannot distinguish between legitimate consumers and potential competitors. The risk for $H$ types is that there may be no such consumers. In reality, for a model with weaker ex post competition, the risk would be that there were too few $L$ types able to secure low ex ante prices to make arbitrage worthwhile. This is a barrier to the effectiveness of ex post arbitrage that has hitherto not been noted by economists.

Of course, this also suggests that monopolist activities directed at limiting the number of $L$ type arbitrageurs will reinforce price discrimination possibilities. The usual reductions in aftermarket competition such as product differentiation, transportation or transaction costs will continue to be relevant as will credible restrictions by the monopolist ex ante; e.g., limits of the volume purchased by $L$ types.

But this also suggests that if consumers could contract ex ante, then prior to dealing with the monopolist, $H$ types will know for sure if $L$ types exist and are able to 
arbitrage utilising lower prices. However, as we demonstrate next, the possibility of ex ante arbitrage itself does not, for similar reasons, prevent the monopolist from engaging in first degree price discrimination.

\section{Ex Ante Arbitrage}

As noted earlier, arbitrage can also occur via forward markets - something we term ex ante arbitrage. In this situation, consumers trade forward purchase agreements with other consumers. In so doing, consumers have knowledge of the type of consumer they are trading with. A consumer who sells a forward contract is then obligated to purchase the requisite goods for that contract from $M$. Of course, in so doing, they will be charged by $M$ a price based on their type and not on the type of consumer they are selling to.

The timing of the ex ante forward market is as follows:

PERIOD 0: $L$ and $H$ consumers trade forward purchase contracts.

PERIOD 1: $M$ makes (unit) price offers of $\bar{p}$ and $\underline{p}$ to $H$ and $L$ types respectively and low and high types choose their quantities. Forward contracts are settled and consumers holding the product consume it.

We need to place some minimal constraints on the behaviour in the forward market and on the interaction between the forward market and the period 1 'spot' market.

In the forward market, there are clearly a wide variety of forward contracts that could potentially be traded in such a market. We limit attention to a highly-flexible subset of these contracts that are relevant for price discrimination: a forward contract will involve the seller agreeing to deliver the purchaser one unit of the relevant product at the end of period 1 , contingent on the period 1 price $p$ not exceeding a particular value. Thus, we can denote a forward contract by its critical price $f$. If a consumer holds one forward contract with critical price $f$ in period 1 then, if $p \leq f$, that consumer will receive one unit of the product from the counterparty in period 1 . If, however, $p>f$, then the holder of the forward contract receives nothing. To eliminate some complexity, we also assume that all forward contracts are rendered void if $\bar{p}<\underline{p}$ and that only $L$ consumers sell forward contracts and these are only purchased by $H$ consumers. This 
latter condition (which holds automatically in the equilibrium below) allows us to focus on price discrimination and avoids trivial issues such as forward trade between consumers with identical valuations. Importantly, this also implies that if there is only one type of consumer then there are no trades in the forward market.

An immediate implication of these assumptions is that there is no trade in forward contracts with critical price $f>\bar{v}$. This reflects the fact that there will be no trade in contracts which might be exercised even though the relevant period 1 price exceeds the value of the product to an $H$ consumer.

The forward markets and spot markets will be linked. In particular, when $M$ sets the prices for its product, these prices may depend on whether or not $M$ can observe the outcome of the forward market and, if $M$ can observe this, what information if any the forward market conveys to $M$. We begin by making the simplest assumption, that $M$ cannot observe the price or trades in the forward market.

While $M$ cannot observe the outcome of the forward market, it will still have beliefs over that outcome. Let $P(f)$ denote the probability that $M$ places on an $H$ consumer having purchased a forward contract with a critical price no lower than $f$. Note that $P(f)$ is non-increasing in $f$.

Given that $M$ learns no relevant information from the forward market then, regardless of the forward trades that actually occur, $M$ will set prices according to the following lemma.

Lemma 2: Without loss of generality, we can restrict attention to situations where the producer sets profit maximising prices $\underline{p} \in\{\underline{v}, \bar{v}\}$ and $\bar{p}=\bar{v}$ in period 1 .

PROOF: In period 1, $M$ has a number of mutually exclusive choices:

(i) $\quad M$ could set $\underline{p} \leq \bar{p} \leq \underline{v}$ and gain expected per consumer profits of $\pi(\underline{p}-c)+(1-\pi) P(\underline{p})(\underline{p}-c)+(1-\pi)(1-P(\underline{p}))(\bar{p}-c) ;$

(ii) $\quad M$ could set $\underline{p} \leq \underline{v}<\bar{p} \leq \bar{v}$ and gain expected per consumer profits of $\pi(\underline{p}-c)+(1-\pi) P(\underline{p})(\underline{p}-c)+(1-\pi)(1-P(\underline{p}))(\bar{p}-c) ;$

(iii) $\quad M$ could set $\underline{v}<\underline{p} \leq \bar{p} \leq \bar{v}$ and gain expected per consumer profits of $(1-\pi) P(\underline{p})(\underline{p}-c)+(1-\pi)(1-P(\underline{p}))(\bar{p}-c) ;$

(iv) $\quad M$ could set $\underline{v}<\underline{p} \leq \bar{v}<\bar{p}$ and gain expected per consumer profits of $(1-\pi) P(\underline{p})(\underline{p}-c)$; 
(v) $\quad M$ could set $\bar{v}<\underline{p} \leq \bar{p}$ and make zero profits;

(vi) $\quad M$ could set $\underline{p}>\bar{p}$.

Further, (i) to (vi) fully characterize $M$ 's pricing options in period 1.

Profits in (i), (ii) and (iii) are increasing in $\bar{p}$. So in (i) $M$ will set $\bar{p}=\underline{v}$ while in (ii) and (iii) $M$ will set $\bar{p}=\bar{v}$. Given this, and remembering that $P(f)$ is nonincreasing in $f$, it is easy to see in (i) that $M$ 's profit maximizing prices are $\underline{p}=\bar{p}=\underline{v}$ which gives $M$ per customer profits of $\underline{v}-c$. Similarly, in (ii), $M$ 's profit maximizing prices are $\underline{p}=\underline{v}$ and $\bar{p}=\bar{v}$ yielding expected per customer profit $[\pi+(1-\pi) P(\underline{v})](\underline{v}-c)+(1-\pi)(1-P(\underline{v}))(\bar{v}-c)$. In (iii), $M$ 's profit maximizing prices are $\underline{p}=\bar{p}=\bar{v}$ with profit $(1-\pi)(\bar{v}-c)$.

Note that in each of these cases, profits are strictly positive so that any of these cases is preferable to (v). Further, it is easy to confirm that (iii) yields at least as high profits as (iv) and that (ii) yields at least as high profits as (i). Thus, if $M$ sets $\underline{p} \leq \bar{p}$, it will be profit maximizing to set $\underline{p} \in\{\underline{v}, \bar{v}\}$ and $\bar{p}=\bar{v}$.

Finally, suppose that $M$ sets $p>\bar{p}$. It is easy to show that this leads to profits for $M$ strictly less than $\underline{v}-c$ if $\underline{p} \leq \underline{v}$. But this is less than the profits from (i) so this can never be profit maximizing. If $\underline{p}>\underline{v}$ then $M$ 's profits are $(1-\pi)(\bar{p}-c)$ if $\bar{p} \leq \bar{v}$ and zero otherwise. Thus if $M$ sets $\underline{p}>\underline{v}$ then its profit maximizing prices are $\bar{v}=\bar{p}<\underline{p}$ and this yields the same profit as the maximized profits in (iii). Thus without loss of generality we can restrict attention to situations where $M$ sets profit maximizing prices $\underline{p} \in\{\underline{v}, \bar{v}\}$ and $\bar{p}=\bar{v}$.

From Lemma 2, we can reduce the profit maximising choice for $M$ to two alternatives. If $M$ price discriminates and chooses $\underline{p}=\underline{v}$ and $\bar{p}=\bar{v}$ then its expected per customer profit is $[\pi+(1-\pi) P(\underline{v})](\underline{v}-c)+(1-\pi)(1-P(\underline{v}))(\bar{v}-c)$. Alternatively, if $M$ does not price discriminate and chooses $\underline{p}=\bar{p}=\bar{v}$ then its expected per customer profit is $(1-\pi)(\bar{v}-c)$

Given this, the following lemma is simply derived by comparing profits under price discrimination where $\underline{p}=\underline{v}$ and $\bar{p}=\bar{v}$ with profits without price discrimination where $\underline{p}=\bar{p}=\bar{v}$.

Lemma 3: $M$ will always price discriminate if $\pi(\underline{v}-c)-(1-\pi) P(\underline{v})(\bar{v}-\underline{v})>0$.

In the presence of a forward market, $M$ will have a reduced incentive to price discriminate. In particular, $M$ 's incentive is reduced to the degree that it believes setting 
discriminatory prices will lead to high consumers exercising their forward contracts and effectively buying the product at the $L$ price. As $P(\underline{v})$ falls, $M$ has a greater incentive to price discriminate and as $P(\underline{v})$ approaches zero (i.e. the forward market ceases to operate) then $M$ will always price discriminate.

Clearly, the likelihood of price discrimination depends on the exact functioning of the forward market and in general this requires a specific market model. However, it is possible to bound $P(\underline{v})$ given our restrictions on the forward market. In particular, we know that $P(\underline{v})<1-\Pi(0)$. This follows because, if there are no $L$ consumers, then no $H$ consumer can purchase a forward contract. Thus:

Proposition 2: The producer $M$ will always price discriminate in period 1 if $\pi(\underline{v}-c)-(1-\pi)(1-\Pi(0))(\bar{v}-\underline{v})>0$.

At this stage, it is worth comparing Propositions 1 and 2. Note that, as in the case of ex post arbitrage, ex ante arbitrage will not eliminate price discrimination if either the probability of any consumer being $L$ is high enough or if $\underline{v}$ and $\bar{v}$ are close enough to each other. Further, price discrimination in the presence of ex ante arbitrage depends on the possibility that the forward market will 'fail' due to a lack of $L$ buyers. This mirrors the result for ex post arbitrage. In each case, price discrimination arises by $M$ trading off the likelihood that the arbitrage market will operate efficiently and the potential gains from selling at a high price to an $H$ consumer.

This said, the presence of ex post and ex ante arbitrage is likely to affect M's pricing behavior in quite different ways. With ex post arbitrage, when price discriminating, $M$ can only charge $H$ consumers a price that does not exceed $\underline{v}$ by too much. An $H$ consumer, when faced with this price, then has to weigh up the benefits of securing the product for certain in period 1 or risk waiting to see if they can purchase the product at a cheaper price in period 2.

In contrast, with ex ante arbitrage, the relevant forward trade occurs prior to the consumers facing $M$. As such, the best that $M$ can do is to always charge a high price to $H$ consumers. The trade-off for $M$ is whether or not it should set a low price to the $L$ consumers at all, knowing that this may lead to a fall in high-price sales as some $H$ consumers may be holding relevant forward contracts. As a result, if price discrimination 
occurs under ex ante arbitrage, the prices set are identical to those under perfect price discrimination. In contrast, with price discrimination in the presence of ex post arbitrage, the $H$ consumer price will be reduced to enhance the trade-off facing the $H$ consumer.

This pricing difference is also reflected in the different conditions in Propositions 1 and 2. In particular, the condition in Proposition 1 is always satisfied whenever the condition in Proposition 2 is satisfied but not vice versa. To see this, note that $\frac{1-\Pi(n)-\Pi(0)}{1-\Pi(n)}=1-\frac{\Pi(0)}{1-\Pi(n)}<1-\Pi(0)$. In this sense, ex post arbitrage creates less of a constraint on price discrimination than ex ante arbitrage. The reason for this is straightforward. With ex ante arbitrage, when an $H$ consumer reaches period 1, they already know the outcome of the forward market and whether there are any $L$ consumers present. In contrast, with ex post arbitrage, when facing $M$, an $H$ consumer has much more limited information. They do not know whether or not there is a low valuation consumer. Indeed, they only know for sure that one consumer, themselves, is not $L$. Thus, $M$ is better able to play on the $H$ consumer's ignorance about other consumers with ex post arbitrage.

This said, like Proposition 1, Proposition 2 only specifies a lower bound condition for price discrimination. If the condition is satisfied then in equilibrium $M$ will definitely engage in price discrimination. However, the actual equilibrium outcome depends on the structure of the forward market. In this sense, there can be no presumption that price discrimination will be more likely under ex post arbitrage than under ex ante arbitrage. The outcome will depend on the efficiency of the arbitrage markets.

In summary, when the monopolist offers discriminatory pricing under ex ante arbitrage, forward contracts 'turn' an $H$ into an $L$; something that would not happen if you offered a single price. So the trade off is a bit like the situation without price discrimination - either set a high price and sell to all $H$ and no $L$ s or price discriminate and sell at a high price to any $H$ without a forward contract and a low price to everyone else. In comparison, the standard no price discrimination alternative is just an extreme version of this: set a high price only and sell to all $H$ s but no $L$ s or set a low price and sell to everyone at the low price.

In deriving Proposition 2, we made a number of assumptions. First, we only considered a specific set of forward contracts. It should be noted that this set includes simple contracts where the seller promises to deliver one unit of the product to the buyer 
subject to the 'efficient trade' constraints defined above. Further, the set of forward contracts we consider is relatively flexible.

Our argument did not specify whether or not $L$ consumers could purchase more than a single unit in period 1 , and our results clearly remain valid regardless.

More importantly, we assumed that $M$ could not observe the outcome of the forward contract trading. This is a critical assumption in deriving Proposition 2. If $M$ can observe the outcome of the forward market then $P(\underline{v})$ will depend on what $M$ observes. Thus, after observing the forward market, $M$ could believe that $P(\underline{v}) \geq 1-\Pi(0)$. Indeed, after observing a particular outcome of the forward market, $M$ may believe that $P(\underline{v})=1$ so that any price discrimination is irrelevant. All $H$ consumers hold a forward contract in this situation and either the producer sells to all consumers at a price of $\underline{v}$ or just sells to $H$ consumers at a price of $\bar{v}{ }^{6}$

Given our information constraint on $M$, we can think of Proposition 2 as best applying to either one of two situations: (a) where $M$ must set prices for each type prior to trade and cannot stop consumers dealing with each other before making any sales; or (b) where the forward market is secret or private so that it cannot be observed by $M$. The former applies to the sale of tickets, for example, to sporting events, where consumers may trade, including accumulating orders with consumers who face a low price, prior to buying from $M$. The latter applies to situations where $M$ tries to ban resale so that any $e x$ ante arbitrage must occur without $M$ 's knowledge.

This latter example raises an additional point. In our model, we have taken the efficiency of the relevant arbitrage market as given. However, it may be possible for $M$ to undermine either ex post or ex ante arbitrage by reducing market efficiency. For example, $M$ could require customers to sign a contract forbidding resale, with penalties if such resale is detected. Generally, we expect that $M$ will have incentives to undermine arbitrage markets in order to improve the efficacy of price discrimination.

\footnotetext{
${ }^{6} M$ could set differential prices but these would be meaningless as no trade would occur at the higher price.
} 


\section{Conclusions}

We have demonstrated here that costless arbitrage does not necessarily constrain the practice of price discrimination. When consumers and the seller do not expect that the number of low valuation consumers will be large, the seller finds it optimal to charge low and high value consumers different prices. Even when consumers can hedge against such risks in forward markets, the monopolist will still use observationally perfect price discrimination if it suspects that the number of potential arbitrageurs is low. This suggests that, at the very least, the textbook condition that arbitrage be impossible or prohibitively costly can be amended with an emphasis on the mass of consumers likely to be of low valuation and engage in arbitrage activities.

To our knowledge, this is the first attempt to consider in detail this particular assumption underlying the feasibility of price discrimination - either first or third degree. While the model is an extreme one in that there is perfect observability of types and very strong re-sale market competition, we believe that the insights from this model may be useful in studies of price discrimination. In particular, strategies that limit effective (as opposed to actual) arbitrage may be usefully employed by sellers wishing to charge different prices to different customers. These include strategies that obscure the nature of discounts being offered and who they are being offered to, their time sensitivity (as in Amazon.com's Gold Box) and also the volume of purchases allowed at discounted prices. Each of these limit effective arbitrage.

It is worth noting that a similar counter-intuitive suggestion has arisen in the study of intellectual property protection. Boldrin and Levine (2002) have argued that innovators and creative artists can still earn a positive return on their activities even in the absence of intellectual property protection. In their model, consumers of innovators can become competitors but only with limited capacity - trading off imitative activities with consumption activities. This friction allows the innovator to earn rents but also to charge consumers more for 'initial copies' as those consumers will be themselves able to earn rents in ex post markets. Here we have similarly permitted consumers to become potential competitors against a monopoly seller. However, in our case, the monopoly seller can still earn supra-competitive profits because of uncertainty regarding the extent 
of ex post market competition and thickness. This suggests that there might be some link between our study here and issues of intellectual property protection. This is a topic for future research. 


\section{References}

Alger, I. (1999), “Consumer Strategies Limiting the Monopolist's Power: Multiple and Joint Purchases,” RAND Journal of Economics, 30 (4), pp.736-757.

Boldrin, M. and D.K. Levine (2002), “The Case Against Intellectual Property,” American Economic Review, 92 (2), pp.209-212.

Choudhary, V., A. Ghose, T. Mukhopadhyay and U. Rajan (2005), "Personalized Pricing and Quality Differentiation,” mimeo., Carnegie Mellon.

Shapiro, C. and H. Varian (1999), Information Rules: A Strategic Guide to the Network Economy, Harvard Business School Press: Boston (MA).

Tirole, J. (1988), The Theory of Industrial Organization, MIT Press: Cambridge (MA).

Varian, H. (1989), "Price Discrimination,” in R. Schmalensee and R. Willig (eds), Handbook of Industrial Organization, Volume 1, North-Holland: Amsterdam, Chapter 10. 